\title{
Concomitant multiple anomalies of renal vessels and collecting system
}

\author{
D. Stojadinovic, I. Zivanovic-Macuzic, P. Sazdanovic, D. Jeremic, M. Jakovcevski, \\ M. Minic, M. Kovacevic \\ Department of Anatomy, Faculty of Medical Sciences, University of Kragujevac, Serbia
}

[Received: 11 August 2019; Accepted: 27 September 2019]

\begin{abstract}
Although anomalies of renal vessels and collecting system are relatively frequent, their concomitant occurrence is a rare event. During dissection of a 75-year-old male formalin-embalmed cadaver, we found multiple variations in the renal vessels and renal collecting system. Both kidneys were normal in size and anteriorly malrotated, with duplex collecting system and duplex ureter. One ureter drained the upper part of the kidney and the second ureter drained the lower part of the kidney. Superior and inferior collecting systems were separated by renal parenchyma. The right kidney had two renal arteries, the first renal artery (main renal artery) originating from the abdominal aorta, passing behind the inferior vena cava (IVC) and entering the kidney through the superior and inferior renal hilum. The second artery was the inferior polar artery. In addition, the right kidney had two renal veins as well. Three renal tributaries emerged from the upper and lower portion of the right renal hilum, and they joined to form the main renal vein which drained into the IVC. The lower renal vein was the inferior polar vein. The left kidney had four renal arteries (two hilar arteries and two polar arteries). The main left renal vein emerged from both superior and inferior left renal hilum, passed in front of the abdominal aorta and drained into the IVC. The left kidney also had the inferior polar vein which was divided behind the aorta (retro aortic vein) into two venous trunks. These venous trunks drained separately into posteromedial aspect of the IVC. Finally, the right testicular vein was formed by two tributaries and drained into the IVC, whereas the two left testicular veins drained separately into the left main renal vein. (Folia Morphol 2020; 79, 3: 627-633)
\end{abstract}

Key words: anatomy, variation, renal artery, renal vein, kidney

\section{INTRODUCTION}

Renal arteries arise from the abdominal aorta, just below the superior mesenteric artery, between the first and the third lumbar vertebrae [7]. In $70 \%$ of the cases, there is a single renal artery [30]. Variations of the main renal and neighbouring vessels are common. Renal arteries vary in their number, origin, mode of branching, and site of entry into the kidney.
The differences in frequency of multiple renal arteries that are described in literature are due to studied population, visualizing techniques and stage of morphological development [12]. The largest percentage of multiple arteries is described by Palmieri et al. [25] in Brazilian population. In their angiographic study, the percentage of multiple arteries was $61.5 \%$ of the pedicles (56\% in the right and $67 \%$ in the left).

Address for correspondence: Dr. I. Zivanovic-Macuzic, Department of Anatomy, Faculty of Medical Sciences, University of Kragujevac, Svetozara Markovica 69, 34000 Kragujevac, Serbia, e-mail: ivanaanatom@yahoo.com 
Hlaing et al. [14] found only $4 \%$ of accessory arteries in the Malaysian population in an anatomical study. The existence of accessory renal arteries is most often without clinical symptoms and is detected at radiological examination accidentally. However, in some cases, presence of accessory arteries can lead to clinical symptoms. Small calibre and tortuous shape of these arteries can lead to ischaemia of part of the kidney and consequent hypertension [28]. Patients with resistant hypertension should be investigated for accessory arteries or renal artery stenosis. If the accessory artery as the lower polar artery passes in front of the ureteropelvic junction, it may lead to external compression and hydronephrosis [31]. Accessory renal arteries may be injured during percutaneous renal biopsy or during other surgical procedures. Zhang et al. [41] reported a rare case of life-threatening bleeding after percutaneous biopsy in patients with accessory renal arteries and renal amyloidosis. The presence of multiple arteries during kidney transplantation requires a longer time for surgery. The requirements of vascular reconstruction and more complex implantation lead to additional ischaemic injuries and subsequent reperfusion injuries during renal transplantation [18]. Damage to the lower polar artery can lead to bleeding and kidney infarction. As the lower polar artery vascularizes the ureteropelvic junction, its damage can lead to pyeloureteral necrosis of the graft [29]. One should be aware that accessory renal arteries are fully functional, and thus their ligation ends up with ischaemic damage.

Each kidney typically has one renal vein, which originates from a variable number of tributaries and drains into the inferior vena cava (IVC). The right renal vein (RRV) is shorter ( $2-4 \mathrm{~cm})$, without any additional tributaries, and enters the right lateral aspect of the IVC. The left renal vein (LRV) is longer than the right $(6-10 \mathrm{~cm})$ [4]. Next to its point of entry into the IVC, the LRV is $12.3 \pm 1.41 \mathrm{~mm}$ in diameter, whereas the $\mathrm{RRV}$ is $10.9 \pm 1.56 \mathrm{~mm}$ wide [6]. If there were more than one renal vein on each side, they were referred to as "accessory renal vein", "multiple renal veins" or "additional renal vein". Left renal vein usually passes in front of the aorta ("preaortic position") but can also pass behind the aorta - "retroaortic left renal vein". The LRV that divides into the ventral and dorsal limbs that surround the abdominal aorta and enter the IVC at different levels is called the "circumaortic LRV". If the venous branches of the LRV joined within $1.5 \mathrm{~cm}$ from the left lateral wall of abdominal aorta or if the venous branches of the RRV joined within $1.5 \mathrm{~cm}$ of the confluence with the IVC then this is the "late venous confluence". The presence of additional renal veins, retro aortic, and circumcortical LRVs has clinical implications in some cases. The retro aortic and circumaortic LRV may be relative contraindications to donor nephrectomy [8]. Retroaortic left renal may be associated with lumbar pain, haematuria, thrombosis, varicocele and splenomegaly [3]. The retro-aortic LRV may be affected by a malignant pancreatic process and injured during that surgery. It can also be injured during retroperitoneal lymphadenectomy in testicular tumours or even during lumbar spine surgery. For donor nephrectomy, the contraindication is the existence of anomalous multiple renal veins because they increase the risk of renal vein graft thrombosis [15]. A single renal vein was described bilaterally in $78.2 \%$ of the samples, whereas $21.8 \%$ of kidneys had additional renal veins [6].

Renal collecting system may be duplicated partially or completely. Estimated prevalence of duplex kidneys ranges between $0.3 \%$ and $6 \%$, with a female preponderance $[13,38]$. Duplicity of the renal collecting system is usually an asymptomatic anomaly and is most commonly detected in childhood and rarely in adults. Duplicity of the renal collecting system can be manifested by recurrent urinary infections, flank pain, incontinence and haematuria [9].

We report the interesting anatomical variations observed during the cadaveric dissection - concomitant multiple anomalies of renal vessels and collecting system.

\section{CASE REPORT}

The study was performed on a 75-year-old deceased man at the Department of Anatomy at Faculty of Medical Sciences, University of Kragujevac, Serbia. During the dissection multiple variations of renal vessels and collecting renal system were found (Figs. 1, 2). The measurements were made by a Vernier calliper with an accuracy of $0.1 \mathrm{~mm}$. The diameters of the renal arteries were measured at the point of their exit from the abdominal aorta, while the diameters of the renal veins were measured at the site of their drainage in the IVC. The length of the renal arteries was measured from the point of origin from the abdominal aorta to the branching point. The length of the renal veins was measured from the point of their origin to the point of entry into the IVC. 


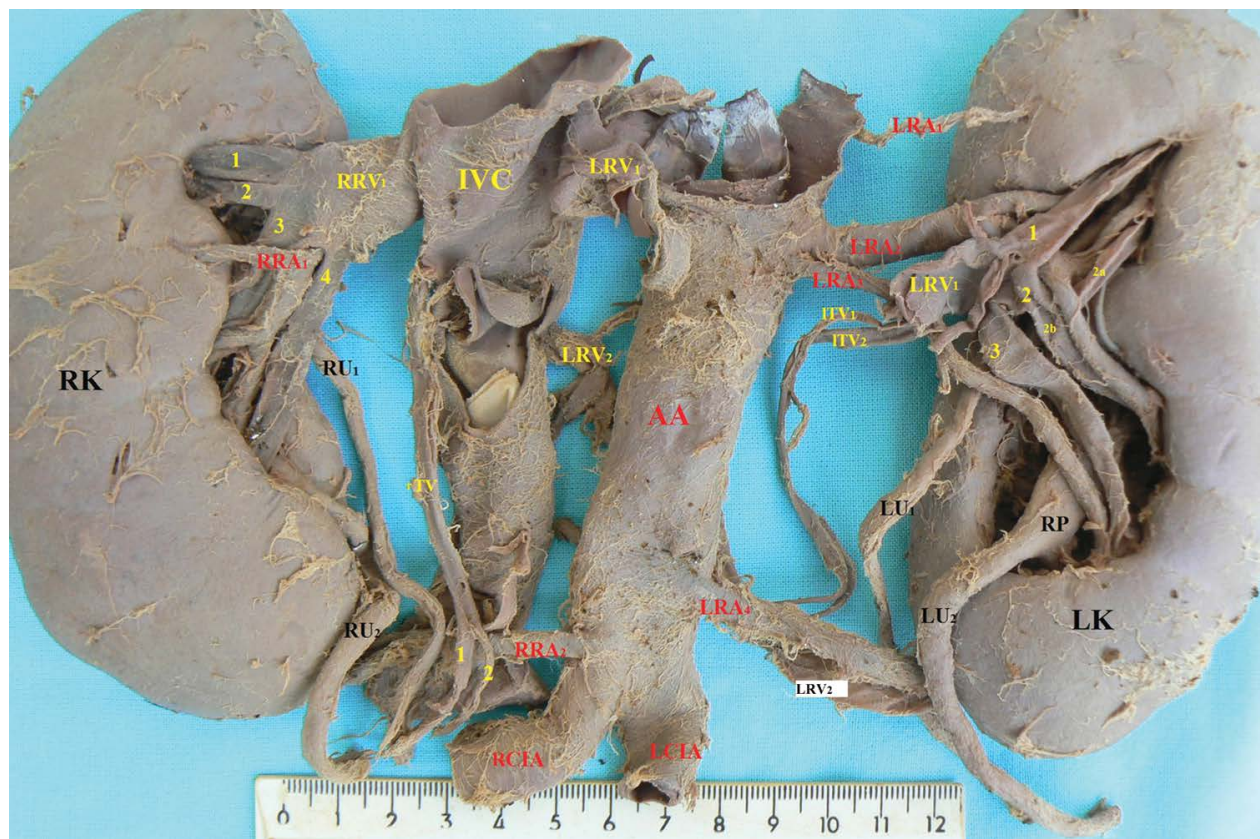

Figure 1. Renal system — front view; IVC — inferior vena cava; AA — abdominal aorta; RK — right kidney; LK — left kidney; RP — renal pelvis; $\mathrm{RU}_{1}$ - the first right ureter; $\mathrm{RU}_{2}$ - the second right ureter; $\mathrm{LU}_{1}$ - the first left ureter; $\mathrm{LU}_{2}$ — the second left ureter; $R R V_{1}$ - the first right renal vein (main right renal vein); $R R A_{1}$ — the first right renal artery; $R R A_{2}$ — the second right renal artery (main renal artery); $R R A_{3}$ the third right renal artery; $R R A_{4}$ - the fourth right renal artery, $L^{2} V_{1}$ - the first left renal vein (main left renal vein); $L_{2} V_{2}$ - the second left renal vein (retroaortic renal vein - lower polar renal vein); RTV - right testicular vein; 1 and 2 - two tributaries of the right testicular vein; ITV 1 - the first left testicular vein; ITV - the second left testicular vein; $\mathrm{rCIA}$ — right common iliac artery; ICIA — left common iliac artery; $1,2,3,4$ - tributaries of the $\mathrm{RRV}_{1} ; 1,2,3$ - tributaries of the $\mathrm{LRV}_{1}$, venous tributary 2 the $\mathrm{LRV}_{1}$ is derived from smaller tributaries $2 \mathrm{a}$ and $2 \mathrm{~b}$.

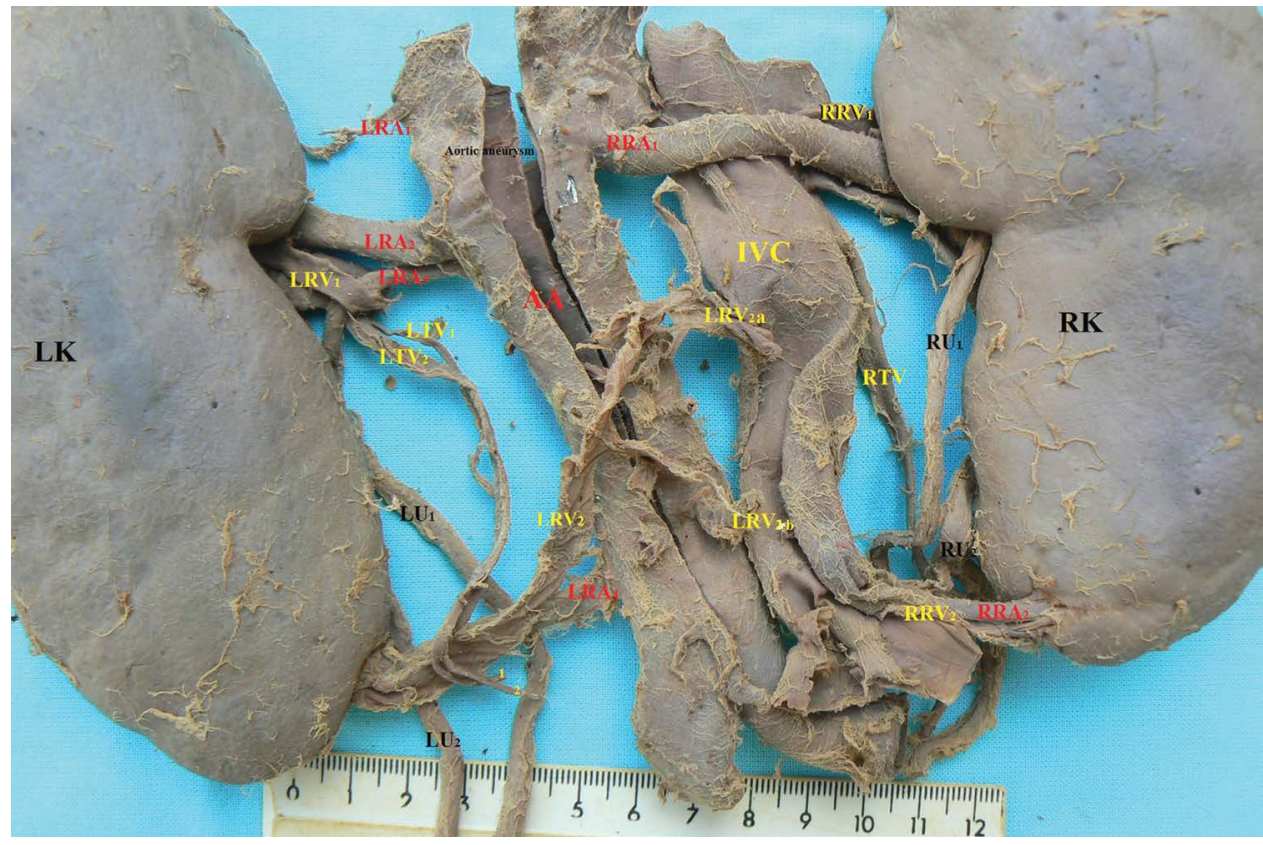

Figure 2. Renal system — back view; IVC — inferior vena cava; AA — abdominal aorta with an aneurysm; RK — right kidney; LK — left kidney; $\mathrm{RU}_{1}$ — the first right ureter; $\mathrm{RU}_{2}$ - the second right ureter; $\mathrm{LU}_{1}$ — the first left ureter; $\mathrm{LU}_{2}$ — the second left ureter; $\mathrm{RRV}_{1}$ - the first right renal vein (main right renal vein); $\mathrm{RRV}_{2}$ — the second right renal vein (inferior polar right renal vein); $\mathrm{LRV}_{1}$ — the first left renal vein (main left renal vein); $\mathrm{LRV}_{2}$ - the second left renal vein — retroaortic left renal vein (inferior polar vein); $\operatorname{LRV}_{2 \mathrm{a}}$ and $\mathrm{LRV}_{2 \mathrm{~b}}$ - two venous trunks of the $\mathrm{LRV}_{2} ; \mathrm{RRA}_{1}$ - the first right renal artery (main right renal artery); RRA - the second right renal artery (inferior polar right renal artery); $L R A_{1}$ - the first left renal artery (superior polar left renal artery); $L R A_{2}$ — the second left renal artery (main left renal artery); $L_{2 R A}$ the third left renal artery (the accessory hilar artery); $\mathrm{LRA}_{4}$ — the fourth left renal artery (inferior polar left renal artery); RTV — right testicular vein; $\mathrm{LTV}_{1}$ — the first left testicular vein; $\mathrm{LTV}_{2}$ — the second left testicular vein. 
Both kidneys were normal in size and ventrally malrotated. Both kidneys had duplex collecting system and duplex ureter. One ureter drained the upper part of the kidney and the other drained the lower part. The superior and inferior collecting systems were separated by renal parenchyma. The right kidney had two arteries. The first right renal artery $\left(\mathrm{RRA}_{1}\right)$ was $7 \mathrm{~mm}$ in diameter at its origin from the abdominal aorta and $50 \mathrm{~mm}$ in length from the point of origin to the point of branching. It was the main right renal artery. The second right renal artery $\left(\mathrm{RRA}_{2}\right)$ was $3 \mathrm{~mm}$ in diameter at its origin from the abdominal aorta and $34 \mathrm{~mm}$ in length from the point of origin to the point of branching. This artery originated from the abdominal aorta just above its division and below the inferior mesenteric artery and entered the kidney through its lower pole (inferior polar artery). The right kidney had two renal veins. The first right renal vein $\left(\mathrm{RRV}_{1}\right)$ was $16 \mathrm{~mm}$ in length from the point of origin to entry into the IVC (very short), with a large diameter at its entrance to the IVC $(11.5 \mathrm{~mm})$. There were four tributaries $(1,2,3$ and 4 in the Fig. 1) which formed the main renal vein on the right side. The two upper tributaries ( 1 and 2 ) emerged from the superior hilum, whereas the two lower tributaries ( 3 and 4) left the inferior hilum. Renal vessels completely covered both renal pelvises anteriorly. The additional right renal vein $\left(\mathrm{RRV}_{2}\right)$ was $2 \mathrm{~mm}$ in diameter at its entrance to the IVC and it originated from the lower pole (inferior polar vein) together with the inferior polar artery and drained into the IVC. It was $45 \mathrm{~mm}$ in length from the point of origin to entry into the IVC. The left kidney had four renal arteries. The first left renal artery $\left(\operatorname{LRA}_{1}\right)$ was $1.5 \mathrm{~mm}$ in diameter and $40 \mathrm{~mm}$ in length. It arose from the aorta $22 \mathrm{~mm}$ above the second renal artery and entered the superior pole of the kidney (superior polar renal artery). The second left renal artery (main renal artery) $\left(\mathrm{LRA}_{2}\right)$ was $7 \mathrm{~mm}$ in diameter and it gave branches for the upper and lower hilum. It was $32 \mathrm{~mm}$ in length from the point of origin to the point of branching. The third left renal artery $\left(\mathrm{LRA}_{3}\right)$ was $3 \mathrm{~mm}$ in diameter at its origin from the abdominal aorta and it arose just below the $\mathrm{LRA}_{2}$ and passed downwards. It was $74 \mathrm{~mm}$ in length and it did not have branches. $\mathrm{LRA}_{3}$ entered the lower hilum, in front of the inferior renal pelvis. It was the accessory hilar right renal artery. The fourth left renal artery $\left(\mathrm{LRA}_{4}\right)$ was $3.2 \mathrm{~mm}$ in diameter at its origin from the abdominal aorta and $55 \mathrm{~mm}$ in length from the point of origin to the point of entry into the lower pole of the kidney. It arose from the abdominal aorta just below the inferior mesenteric artery. It entered the left kidney through the inferior pole (inferior polar artery) along with the polar renal vein. The left kidney had an elaborate venous system. The left main renal vein $\left(\mathrm{LRV}_{1}\right)$ was $14.5 \mathrm{~mm}$ in diameter at its entrance to the IVC and $62 \mathrm{~mm}$ in length from the point of origin to entry into the IVC. It crossed in front of the abdominal aorta and received two testicular veins from below left testicular veins - ITV 1 and ITV IT $_{2}$ LRV $_{1}$ was formed by three tributaries (1, 2 and 3 in the Fig. 1) which emerged from the upper and lower hilum. The second left renal vein $\left(\mathrm{LRV}_{2}\right)$ arose from the lower pole (inferior polar vein) of the left kidney together with the inferior polar artery. It ascended and was divided behind the aorta into two venous trunks $\left(L_{2 R} V_{2 a}\right.$ and $\left.L R V_{2 b}\right)$ which drained separately into the posteromedial aspect of IVC. This second left renal vein $\left(\operatorname{LRV}_{2}\right)$ was retro aortic renal vein and bifid renal vein because it had two drainage points in the IVC. Two left testicular veins (ITV $1-2 \mathrm{~mm}$ in diameter and $\mathrm{ITV}_{2}-3 \mathrm{~mm}$ in diameter), arising separately from the ipsilateral pampiniform plexus, ran vertically in parallel to each other, and each one independently terminated at the left renal vein. The right testicular vein (rTV $-3 \mathrm{~mm}$ in diameter) was formed by two tributaries (1 and 2) and as a single vein drained into the IVC immediately below the right main renal vein.

\section{DISCUSSION}

Variations of the main renal artery are common, due to the existence of several mesonephric arteries in the foetal life. These arteries develop from the aorta between C6 and L3 vertebrae. Only one of the mesonephric arteries will be later transformed into the main renal artery [34]. If the renal artery originates above the celiac trunk, it could be due to the persistence of mesonephric vessel [16]. Intrathoracic origin of the left renal artery was described by Stinson et al. [32]. The classification of multiple renal arteries is difficult. We found in the literature a lot of terms for renal arteries: "main", "accessory", "aberrant", "anomalous", "supernumerary", "additional", "supplementary", "multiple", "accessory aortic hilar", "aortic superior polar", "aortic inferior polar", "upper polar artery", and "lower polar artery". Graves [11] first describes the "accessory" renal arteries which originate from the abdominal aorta and enter the kidney through the renal hilum along with the main renal artery. He described additional renal arteries that 
do not originate from the abdominal aorta and do not enter through the kidney hilum as "aberrant" arteries. Türkvatan et al. [35] divided additional renal arteries according to the mode of entry into the kidney into the hilar and polar arteries. The term "main" renal artery refers to the artery with the greatest diameter that enters the hilum of the kidney and vascularizes the largest part of the kidney. In our case, we found six arteries, two on the right and four on the left kidney.

The "main" renal artery was RRA ${ }_{1}$ on the right kidney and $L R A_{2}$ on the left kidney. Other arteries RRA $_{2}, \mathrm{LRA}_{1}, \mathrm{LRA}_{3}$, and LRA 4 are accessory (multiple, additional, supplementary, supernumerary) arteries. The accessory artery may be a hilar or aberrant (polar) artery. In our case $\mathrm{LRA}_{3}$ is an "accessory aortic hilar" renal artery. Other arteries RRA, LRA $_{1}$ and $\mathrm{LRA}_{4}$ are polar arteries because they enter the kidney through the poles. LRA, is in our case upper polar renal artery, and $\mathrm{RRA}_{2}$ and LRA $\mathrm{L}_{4}$ are the lower polar renal arteries. Alternative nomenclatures have been used to describe the accessory renal artery as multiple, supplementary, additional, supernumerary arteries, etc. All these terms indicate that in addition to the main renal artery, there is also some artery that originates from the aorta or surrounding arteries and enters the kidney through its hilum or kidney capsule. These accessory/aberrant renal arteries usually originate from the abdominal aorta or iliac arteries and less frequently from the lower thoracic aorta or from the lumbar or mesenteric arteries [37]. If the right renal artery branches in the retrocaval part and the left renal artery at a distance of less than $1.5 \mathrm{~cm}$ from the aortic origin, then we are talking about the "pre-hilar or early division" of the renal artery. Satyapal et al. [28] and Özkan et al. [24] described two types of the additional renal arteries: (1) early division arteries and (2) extra renal arteries, which are classified as hilar (accessory) arteries and polar (aberrant) arteries. Multiple renal arteries were discovered in $22 \%$ of subjects and $12.12 \%$ of kidneys in the study of Tardo et al. [33] A single renal artery was described in $93.1 \%$ of the samples, while $5.6 \%$ of kidneys had two arteries. In only $1.4 \%$ of kidneys there were three arteries. Variations among males were more than females ( $27.2 \%$ vs. $15.2 \%$ ) [33]. It was described that $64.3 \%$ of the patients with renal artery variation also had hepatic artery and/or coeliac trunk variation. The relation between the coeliac trunk and/or hepatic artery variations and renal artery variations was significant [36]. Bilateral variation in the arterial patterning was approximately $10 \%$ [23].
Wróbel et al. [39] found four left renal arteries in a 75-year-old female volunteer body donor. Kinnunen et al. [20] described a kidney with ten arteries. In an angiographic study Çınar and Türkvatan [7], multiple renal arteries were found in $31.3 \%$ of cases (two arteries in $22.2 \%$, three in $7.5 \%$, four in $1.4 \%$, five in $0.2 \%$ cases) and prehilar branching in $6.5 \%$ cases.

The venous system arises from three paired veins: the cardinal veins, vitelline veins, and umbilical veins. The IVC develops from the posterior cardinal vein, right supracardinal vein, right subcardinal vein, and right vitelline vein [40]. Studies suggest that variation in venous patterning has an incidence of $23.5-30 \%$, as observed through computed tomography [21, 42]. Congenital venous anomalies in the retroperitoneal space are classified into five groups: 1) type I - retro aortic LRV which joins the IVC in ortotopic position $(0.3-0.9 \%) ; 2)$ type II - LRV that joins the IVC lower, at L4-L5 (0.4-0.9\%); 3) circumaortic renal collar $(0.5-1.4 \%)$; 4 ) duplication of IVC $(0.2-3 \%)$, and 5) left-sided IVC (0.2-0.5\%) [2]. Angiographic studies have shown right renal vein multiplicity in $21.6 \%$ of cases (two RVs in $19.2 \%$, three RVs in $2.2 \%$ and four $\mathrm{RV}$ s in $0.2 \%$ cases). The prevalence of the circumaortic LRV was $5.2 \%$, retro aortic LRV was $4.2 \%$ and, late venous confluence was $7.3 \%$. There was no gender difference in renal artery and vein variations [7]. Janschek et al. [17] reported about cases of multiple renal veins. Their study showed that variations were more common on the right side $(23 \%)$ than on the left $(6.7 \%)$. In the study on left renal vein variations, renal collars were found in $0.3 \%$, retro-aortic vein in $0.5 \%$, additional veins in $0.4 \%$, [27]. Variations of testicular vessels are more frequent. Abnormalities in the involution of the intersubcardinal anastomosis lead to the variation of the testicular veins. They vary in their number, course and place of termination. The right testicular vein is a tributary of the IVC. Variations of the right testicular vein are very rare. Asala et al. [5] have reported the termination of the right testicular vein into the right renal vein. We found the main right renal vein $\left(R_{R V}\right)$ which was normally positioned and drained into the IVC and the right inferior polar vein $\left(\mathrm{RRV}_{2}\right)$ which drained into the IVC just above the conjunction of the iliac veins. On the left side we noticed the main renal vein $\left(\operatorname{LRV}_{1}\right)$ which had preaortic position and the inferior polar renal vein $\left(\mathrm{LRV}_{2}\right)$ which had retroaortic position. $\mathrm{LRV}_{2}$ was divided behind the aorta into two venous trunks $\left(\operatorname{LRV}_{2 \mathrm{a}}\right.$ and $L_{R V}{ }_{2 b}$ ) which drained separately into the IVC. Some 
authors have found an association of retroaortic and circummaortic left renal veins with pelvic varicosities, varicoceles, thrombosis, hypertension, and haematuria $[19,22]$. The description of the renal vascular pattern on the preoperative imaging facilitates the dissection of these vessels. Therefore, the accurate knowledge of the variations in renal vasculature is of crucial importance for interventions involving the kidney arteries or abdominal aorta. The variations in renal arterial patterning may be of great significance if they are coupled with hypertension or if they require visualization for surgical resection, transplantation, or percutaneous access. These anatomical variations of the renal vessels must be kept in mind to prevent bleeding by an accidental lesion of these vessels.

Variation in ureteral patterning is not as common as the one found in the vascular system, but reports indicate an approximate incidence of $1 \%$ [1]. Unilateral duplex kidney reported by Privett et al. [26] was as high as $1.8 \%$. Duplication of the ureters is a relatively common congenital anomaly with an incidence of $0.7 \%$ in the population [10]. In our case there was bilateral duplex urine collecting system with duplication of ureters, which is a very rare anomaly.

\section{CONCLUSIONS}

Our findings are important for surgeons, because they provide them with the extensive preoperative knowledge of the renal vessels necessary for selecting the proper kidney during donor nephrectomy. The anatomical knowledge may be important for academic, surgical and radiological procedures. This case is very complicated and interesting. In the literature reviewed, we found similar variations in the arteries, veins, or collecting system of the kidney, but did not find an identical case with all these variations on one pair of kidneys.

\section{Acknowledgements}

This paper was supported by project grants No. 175014 and 175007.

\section{REFERENCES}

1. Alberts VP, Minnee RC, van Donselaar-van der Pant KA, et al. Duplicated ureters and renal transplantation: a case-control study and review of the literature. Transplant Proc. 2013; 45(9): 3239-3244, doi: 10.1016/j.transproceed.2013.06.012, indexed in Pubmed: 24182792.

2. Aljabri B, MacDonald PS, Satin R, et al. Incidence of major venous and renal anomalies relevant to aortoiliac surgery as demonstrated by computed tomography. Ann Vasc Surg. 2001; 15(6): 615-618, doi: 10.1007/s10016-0010095-7, indexed in Pubmed: 11769141.
3. Anjamrooz $\mathrm{SH}$, Azari $\mathrm{H}$, Abedinzadeh $\mathrm{M}$. Abnormal patterns of the renal veins. Anat Cell Biol. 2012; 45(1): 57-61, doi: 10.5115/acb.2012.45.1.57, indexed in Pubmed: 22536553.

4. Anson BJ, Daseler EH. Common variations in renal anatomy, affecting blood supply, form, and topography. Surg Gynecol Obstet. 1961; 112: 439-449, indexed in Pubmed: 13683701.

5. Asala S, Chaudhary S, Masumbuko-Kahamba N, et al. Anatomical variations in the human testicular blood vessels. Ann Anat. 2001; 183(6): 545-549, doi: 10.1016/ s0940-9602(01)80064-9.

6. Ballesteros LE, Saldarriaga V, Ramirez LM. Morphologic evaluation of the renal veins: a study with autopsy material from Colombian subjects. Rom J Morphol Embryol. 2014; 55(1): 77-81, indexed in Pubmed: 24715169.

7. Çınar C, Türkvatan A. Prevalence of renal vascular variations: Evaluation with MDCT angiography. Diagn Interv Imaging. 2016; 97(9): 891-897, doi: 10.1016/j. diii.2016.04.001, indexed in Pubmed: 27178758.

8. Eldefrawy A, Arianayagam M, Kanagarajah $P$, et al. Anomalies of the inferior vena cava and renal veins and implications for renal surgery. Cent European J Urol. 2011; 64(1): 4-8, doi: 10.5173/ceju.2011.01.art1, indexed in Pubmed: 24578852.

9. Gao Z, Wu J, Lin C, et al. Transperitoneal laparoscopic heminephrectomy in duplex kidney: our initial experience. Urology. 2011; 77(1): 231-236, doi: 10.1016/j.urology.2010.02.002, indexed in Pubmed: 20381844.

10. Gay SB, Armistead JP, Weber ME, et al. Left infrarenal region: anatomic variants, pathologic conditions, and diagnostic pitfalls. Radiographics. 1991; 11(4): 549-570, doi: 10.1148/radiographics.11.4.1887111, indexed in Pubmed: 1887111.

11. Graves FT. The aberrant renal artery. J Anat. 1956; 90(4): 553-558, indexed in Pubmed: 13366870.

12. Gulas E, Wysiadecki G, Cecot T, et al. Accessory (multiple) renal arteries - Differences in frequency according to population, visualizing techniques and stage of morphological development. Vascular. 2016; 24(5): 531-537, doi: $10.1177 / 1708538116631223$, indexed in Pubmed: 26945775.

13. Gundeti MS, Ransley PG, Duffy PG, et al. Renal outcome following heminephrectomy for duplex kidney. J Urol. 2005; 173(5): 1743-1744, doi: 10.1097/01. ju.0000154163.67420.4d, indexed in Pubmed: 15821573.

14. Hlaing KP, Das S, Sulaiman IM, et al. Accessory renal vessels at the upper and lower pole of the kidney: a cadaveric study with clinical implications. Bratisl Lek Listy. 2010; 111(5): 308-310, indexed in Pubmed: 20568426.

15. Holden A, Smith A, Dukes P, et al. Assessment of 100 live potential renal donors for laparoscopic nephrectomy with multi-detector row helical CT. Radiology. 2005; 237(3): 973-980, doi: 10.1148/radiol.2373041303, indexed in Pubmed: 16304115.

16. Ichikawa $T$, lino $M$, Koizumi J, et al. A case of right renal artery originating from the thoracic aorta. Jpn J Radiol. 2014; 32(12): 716-720, doi: 10.1007/s11604-014-0360-7, indexed in Pubmed: 25217879.

17. Janschek ECS, Rothe AU, Hölzenbein TJ, et al. Anatomic basis of right renal vein extension for cadaveric kidney 
transplantation. Urology. 2004; 63(4): 660-664, doi: 10.1016/j.urology.2003.11.010, indexed in Pubmed: 15072874.

18. Kadotani $Y$, Okamoto $M$, Akioka $K$, et al. Management and outcome of living kidney grafts with multiple arteries. Surg Today. 2005; 35(6): 459-466, doi: 10.1007/s00595-0042967-2, indexed in Pubmed: 15912293.

19. Karazincir S, Balci A, Görür $S$, et al. Incidence of the retroaortic left renal vein in patients with varicocele. J Ultrasound Med. 2007; 26(5): 601-604, doi: 10.7863/ jum.2007.26.5.601, indexed in Pubmed: 17460002.

20. Kinnunen J, Tötterman S, Tervahartiala P. Ten renal arteries. Eur J Radiol. 1985; 5(4): 300-301, indexed in Pubmed: 4085494.

21. Koc $Z$, Ulusan $S$, Oguzkurt $L$, et al. Venous variants and anomalies on routine abdominal multi-detector row CT. Eur J Radiol. 2007; 61(2): 267-278, doi: 10.1016/j. ejrad.2006.09.008, indexed in Pubmed: 17049792.

22. Koc Z, Ulusan S, Oguzkurt L. Association of left renal vein variations and pelvic varices in abdominal MDCT. Eur Radiol. 2007; 17(5): 1267-1274, doi: 10.1007/s00330006-0440-x, indexed in Pubmed: 17039365.

23. Kornafel O, Baran B, Pawlikowska I, et al. Analysis of anatomical variations of the main arteries branching from the abdominal aorta, with 64-detector computed tomography. Pol J Radiol. 2010; 75(2): 38-45, indexed in Pubmed: 22802775.

24. Ozkan U, Oğuzkurt L, Tercan F, et al. Renal artery origins and variations: angiographic evaluation of 855 consecutive patients. Diagn Interv Radiol. 2006; 12(4): 183-186, indexed in Pubmed: 17160802.

25. Palmieri BJ, Petroianu A, Silva LC, et al. Study of arterial pattern of 200 renal pedicle through angiotomography. Rev Col Bras Cir. 2011; 38(2): 116-121, doi: 10.1590/ s0100-69912011000200009, indexed in Pubmed: 21710050.

26. Privett JT, Jeans WD, Roylance J. The incidence and importance of renal duplication. Clin Radiol. 1976; 27(4): 521-530, doi: 10.1016/s0009-9260(76)80121-3, indexed in Pubmed: 1000896.

27. Satyapal KS, Kalideen JM, Haffejee AA, et al. Left renal vein variations. Surg Radiol Anat. 1999; 21(1): 77-81, doi: 10.1007/BF01635058, indexed in Pubmed: 10370998.

28. Satyapal KS, Haffejee AA, Singh B, et al. Additional renal arteries: incidence and morphometry. Surg Radiol Anat. 2001; 23(1): 33-38, doi: 10.1007/s00276-001-0033-y, indexed in Pubmed: 11370140.

29. Sebastià C, Peri L, Salvador R, et al. Multidetector CT of living renal donors: lessons learned from surgeons. Radiographics. 2010; 30(7): 1875-1890, doi: 10.1148/ rg.307105032, indexed in Pubmed: 21057125.

30. Standring S. (Ed). Gray's Anatomy-The Anatomical Basis of Clinical Practice. Elsevier Churchill Livingstone Publishers, London 2005.
31. Stephens F. Ureterovascular hydronephrosis and the "aberrant" renal vessels. J Urol. 1982; 128(5): 984-987, doi: 10.1016/s0022-5347(17)53308-x.

32. Stinson JM, Rivard AL, Mitchell ME. Intrathoracic origin of the left renal artery. J Vasc Surg. 2016; 64(6): 1851-1852, doi: 10.1016/j.jvs.2015.06.052, indexed in Pubmed: 27871500.

33. Tardo DT, Briggs C, Ahern G, et al. Anatomical variations of the renal arterial vasculature: An Australian perspective. J Med Imaging Radiat Oncol. 2017; 61(5): 643-649, doi: 10.1111/1754-9485.12618, indexed in Pubmed: 28466967.

34. Türkvatan A, Ozdemir M, Cumhur T, et al. Multidetector $\mathrm{CT}$ angiography of renal vasculature: normal anatomy and variants. Eur Radiol. 2009; 19(1): 236-244, doi: 10.1007/ s00330-008-1126-3, indexed in Pubmed: 18665365.

35. Türkvatan A, Akinci S, Yildiz S, et al. Multidetector computed tomography for preoperative evaluation of vascular anatomy in living renal donors. Surg Radiol Anat. 2009; 31(4): 227-235, doi: 10.1007/s00276-008-0428-0, indexed in Pubmed: 18953477.

36. Ugurel MS, Battal B, Bozlar U, et al. Anatomical variations of hepatic arterial system, coeliac trunk and renal arteries: an analysis with multidetector CT angiography. $\mathrm{Br} J$ Radiol. 2010; 83(992): 661-667, doi: 10.1259/bjr/21236482, indexed in Pubmed: 20551256.

37. Urban BA, Ratner LE, Fishman EK. Three-dimensional volume-rendered $\mathrm{CT}$ angiography of the renal arteries and veins: normal anatomy, variants, and clinical applications. Radiographics. 2001; 21(2): 373-386, doi: 10.1148/ radiographics.21.2.g01 mr19373, indexed in Pubmed: 11259702

38. Williams H. Renal revision: from lobulation to duplication: what is normal? Arch Dis Child Educ Pract Ed. 2007; 92(5): ep152-ep158, doi: 10.1136/adc.2007.126680, indexed in Pubmed: 17895266.

39. Wróbel G, Spałek M, Kuchinka J, et al. Four left renal arteries: a rare variant of kidney arterial supply. Folia Morphol. 2019; 78(1): 208-213, doi: 10.5603/FM.a2018.0046, indexed in Pubmed: 29802718.

40. Yagel S, Kivilevitch Z, Cohen SM, et al. The fetal venous system, part I: normal embryology, anatomy, hemodynamics, ultrasound evaluation and Doppler investigation. Ultrasound Obstet Gynecol. 2010; 35(6): 741-750, doi: 10.1002/uog.7618, indexed in Pubmed: 20205155.

41. Zhang Q, Ji Y, He T, et al. Ultrasound-guided percutaneous renal biopsy-induced accessory renal artery bleeding in an amyloidosis patient. Diagn Pathol. 2012; 7: 176, doi: 10.1186/1746-1596-7-176, indexed in Pubmed: 23231829.

42. Zhu J, Zhang L, Yang Z, et al. Classification of the renal vein variations: a study with multidetector computed tomography. Surg Radiol Anat. 2015; 37(6): 667-675, doi: 10.1007/ s00276-014-1403-6, indexed in Pubmed: 25567101. 